\title{
The Role of Business Process Model in Customer Centric eGovernment System
}

\author{
Ramani. S \\ ISRO Headquarters, Bengaluru - 5600094/ \\ Research Scholar, Dr. M.G.R Educational and Research \\ Institute University, Chennai-600095, India.
}

\author{
Y.S.Kumaraswamy \\ Dayananda Sagar College Engineering, \\ Bengaluru - 560078, India.
}

\begin{abstract}
The development of customer centric eGovernment systems, for better services and reliable information to citizen, is increasing in developed and developing countries as part of eGovernment initiatives. This provides an opportunity to redesign government processes and also to improve efficiency and effectiveness within government institution. A review of literature indicates that the majority of eGovernment-fordevelopment projects fail either totally or partially. The gap between design and the ground reality is defined as 'designreality gaps'. This is attributed as the cause of failure. Therefore, this research study has been undertaken to propose a business process model for customer centric eGovernment system that will help to reduce the gap due to business process representation in Information System. This study has revealed that work system in eGovernment can be described as an event (Request) driven system with a pattern Request-ProcessResponse. This paper reports that Process Aware Information System (PAIS) is one of the suitable Information Systems for a customer centric eGovernment system. The process model chosen in PAIS is tightly-framed and workflow system, which includes $\mathrm{P} 2 \mathrm{~A}($ Person-to-Application) and $\mathrm{A} 2 \mathrm{~A}$ (Application-toApplication) process model. The structure of process model proposed for eGovernment system is a multi-tier, non-linear and iterative structure and can be with multiple interconnected descriptive task chains. The work articulation can be represented as descriptive task chains to follow a planned task sequence determined by conditions and situations emerged during process cycle. This process model has been validated with a typical citizen centric eGovernment system.
\end{abstract}

\section{Keywords}

eGovernment, Information System, event driven system, process model, business process map

\section{INTRODUCTION}

The eGovernment concept introduced in the late 1990s was not clearly defined and understood by scholars and practitioners of public administration. Though, e-government was adopted by public administration, the expected outcome has not been obtained [1]. "eGovernment is narrowly defined as the production and delivery of government services through IT applications; however, it can be defined more broadly as a way IT is used to simplify and improve transactions between governments and other actors, such as constituents, businesses, and other governmental agencies" [2].

The impact of eGovenment and use of World Wide Web for the improvement of service delivery, democratic responsiveness and public outreach have been assessed [3]. eGovernment can be the most productive variant of the traditional government, if it is well introduced and managed. Electronic governance
(eGovernance) can be developed in joint administration, if it is well built and supported in a proper manner.

It was noted that a majority of eGovernment projects fail either totally or partially. The gap between design and the ground reality is defined as 'design-reality gaps'. This is attributed as the cause of failure. The design-reality gaps can be found in various dimensions like information, process, objectives, values, management structure etc. The larger design-reality gap may lead to failure of eGovernment project [4]. The success of eGovernment project may be achieved by reducing the design-reality gap. The design-reality gap in design and modeling of business process and its implementation in Information System have been taken for investigation. A business process is a special type of process, which can be defined as a set of tasks or actions that can be carried out in a specific order by assigned employees or other resources based on input data to produce necessary output data in satisfying business goals. The business processes in government system are found to be very complex.

This paper addresses gaps found in generating business processes from functional requirements for eGovernment system during requirements analysis stage. The challenges are found in extracting the details from domain experts and put them in understandable form. Hence, we decided to carry out research study on government work system and its business processes to evolve a suitable model for representing business processes of eGovernment system and to minimize the gap. This model can be used for designing Information System. The stakeholders of eGovernment system can understand system behaviour from this model. This model is not technology dependent. It supports for system development and maintenance. Section 2 describes research problem taken for investigation. Section 3 presents literature survey. The methodology of research is explained in section 4 . The research study and findings are presented in section 5 . The discussions on advantages of the proposed process model are included in section 6. A case study to validate the proposed model is illustrated in section 7. Section 8 summarizes the conclusions.

\section{RESEARCH PROBLEM}

The main objectives of this research study are to understand work system of Government with reference to delivery of services or products to customer; to analyze business process and derive a pattern amenable for service orientation; to propose a business process model with the pattern; to evolve a suitable Information System. The sub objectives are: To improve government institutions functioning in conducting their business; A systematic analysis of each process to ensure its rationality and simplicity; Identification of redundant steps, simplification, adoptable to governance; Provision of law, 
rules, regulations, instructions, codes and manuals to be the basis. This research study considered government system in India.

\section{LITERATURE SURVEY}

IT designers are aware of the technology but they are not aware of the government processes. Politicians and Public officials are aware of the government processes but they do not understand technology [4]. Stakeholders generate requirements based on their understanding of real world objects or processes [5]. The relation between objects/processes is also captured to implement in software for control and monitoring [6]. Programmers generate software specifications in their known languages including relations between input and output for processing. The non- functional goals are captured to represent accurately the state of input/output software objects $[7,8]$.

"Requirements specifications are formulated in a precise way from the requirements and assumptions. Requirements specifications may suffer a great variety of deficiencies like inadequacies with respect to real needs, incompleteness, contradictions, ambiguities, etc." [9]. The perspectives of Requirements Engineering (RE) is to consider business goals, plans, processes, etc. in order to develop systems to meet organizational goals [10]. Modeling is one of the methodologies in Requirements Engineering. The models help in analysis, elicitation, specification, assessment, negotiation and documentation of requirements. It is reported that the current research in RE is development of techniques for modeling and specification [11].

The eight different potential types or models in an eGovernment system are G2C; C2G;G2B;B2G;G2G;G2N;N2G and G2E where $\mathrm{C}$ refers to Citizen, $\mathrm{G}$ refers to Government, $\mathrm{E}$ refers to Employee and $\mathrm{N}$ refers to Nonprofit. It is noted that studies on administrative interface, digital administration and virtual organization in eGovernment will benefit for development of theories and practices of public administration in $21^{\text {st }}$ century [12]. The different stages like cataloguing, transaction, vertical integration and horizontal integration have been proposed as part of 'stages of growth' model in eGovernment system [13]. The terms Street level bureaucracies and System level bureaucracies have been defined. (i.e. The direct contact of Public servants with Citizen has been shifted to Information Systems involving decision making). The perspectives of demand side requirements of Citizen are relatively new and more works need to be done [14].

To increase public value, there is a need for eGovernment system to be knowledge based, user centric, distributed and networked. The use of technology as a tool is to modernize structures, processes, regulatory frameworks, human resources and the culture of public administration [15]. The business rules in public administration represent a complete knowledge about business processes and their behaviour. The rule driven methodology has been proposed for process design envisaging changes in both internal and external environments [16]. In a Business-to-Government process, a formal business process model including the legal constraints to be used as a reference model for workflow implementation is described [17]. The introduction of a holistic framework for the modeling and the management of applications in e-government is discussed. The need for Business Process Management methodology for public sector is described [18].

\section{METHODOLOGY}

Information system is an applied discipline. The research should attempt to improve processes and practices in the system. "The process of qualitative research is inductive, (i.e. conclusions are derived from a set of observations), in which the researcher builds abstractions and concepts and generates theories from details" $[19,20]$. Case study research methods have been used extensively to understand the impact of Information Technology methods on work systems in organizations. The qualitative research with case study method has been chosen for this research study.

We framed the following research questions for our investigation. 1) What kind of work system is existing in government organization? 2) Is there a pattern in business process of government system? 3) What do stakeholders want from eGovernment system? 4) How people, process and technology are linked in government system? 5) How does business process modeling help in development of Information System?

The research study was aimed at obtaining answers to research questions. To assist our research study, data source selected were interviews, literature, government documents and large eGovernment software systems developed by external agencies. Questionnaires were prepared to collect data from field survey. The interviews were conducted to elicit the participants' answers and views. The participants were selected from a group consisting of government officials (management), domain experts, developers, internal users and customers. The data collected was analyzed to extract information about business process and its impact in Information System. The articulation of business process, decomposition of business process, linking of work system to Information System were our aim of this research work.

\section{RESEARCH STUDY AND FINDINGS}

We carried out desk study research and field survey using questionnaires to understand clearly functioning of government system, government processes, customer centricity and viewpoints of stakeholders. Our case study included few Information Systems, which have been developed for local city government and central government in India. The concepts, patterns, constructs and designs derived out of this study are detailed in the following sections.

\subsection{Work System in Government organization}

The manner in which government institutions in India conduct their business has evolved over a period of time and is codified in different statutes, Rules, regulations and procedural manuals enacted or formulated over a wide span of time (with many processes even continuing from colonial period). A statute is a formal written enactment of a legislative authority that governs a state, city or country. As a source of law, statutes are considered primary authority. Ideally all statutes must be in harmony with the fundamental law of the land (constitutional). Rule and Ruling usually refers to standard activities. A business rule is a rule pertaining to the structure or behaviour which is internal to a business. A written instrument containing rules having the force of law is referred to as a regulation.

Every Government organization can be decomposed into functional units, each of which performs a set of interlinked activities. A functional unit is responsible to perform a specific function. According to Business, a function represents active elements and it models the tasks or activities within the company. Functions describe transformations from an initial state to a resulting state. In case of different resulting states occurring, the selection of the respective resulting state can be modeled as a decision function. Activities that are clubbed 
together into a function are not required to be performed sequentially. When activities are clubbed together to form a sequential chain, they form a business process. A business process usually results in the output of goods/products and services to the external world. These outputs are called "services". The business processes that produce product or service to external user are called a primary processes. The business processes essential to effective management of the business are called support processes. A procedure refers to a standard step-by-step instruction to achieve a desired result.

Based on this study, we derive the following characteristics of work system of a functional unit in government organization in order to capture the reality.

- Government organization can be decomposed into functional units.

- Each functional unit consists of at least one function.

- Each function can have one or more business processes.

- Each business process can have one activity or a set of activities forming a sequential chain.

- Each business process performs the required operations on the input and generates output ( service or product)

- Each activity carries out the work based on government procedures to achieve the desired result.

- Human participation (Internal User) at the activity level happens during verification, recommendation, and decision making. The interaction of the internal user(s) is/are required in the work process.

- The operation of business process may take a single cycle or more than one cycle. It may be required to repeat some of the activities in the sequential chain based on situations and conditions in order to generate desired services or products.

- The procedures, rules, regulations and statutes may change over time. Hence, there is a need to update these changes appropriately in the business process so that accuracy of the process is ensured. The flexibility to accommodate these changes as and when they happen is to be provided.

- $\quad$ The required input(s) from customer to operate a business process is/are defined.

- The output(s) generated from a business process is defined explicitly.

\subsection{Pattern in Government Business Process}

Based on the understanding of the work process detailed in 5.1 and the survey data collected from government officials and government documents, we searched for a pattern in customer centric government system :

- Customer applies for a) service, b) certificate, c) permission, d) licence etc. to Government. This can be termed as a service or product generated by a well defined function in the government.

- $\quad$ Statutes, Policies, Procedures, Acts, Rules and Regulations serve as governing framework for evaluation or processing of application forms submitted for required product or service

- Internal user(s) of government or designated functionaries in government apply their knowledge in processing the applications with necessary documents provided as input and accord necessary approvals if found to be in order. Otherwise the applications are rejected.

- Customer pays necessary fees or service charges, if applicable, on demand from government.

- Functionaries issue receipts on accepting payment
- Finally, necessary output (service or product) is generated and delivered to customer.

Further, the internal structure of government process of a particular function in handling the application form of the customer (end-to-end processing) can be obtained in abstract form.

The internal structure exhibits that the application form goes through various stages of processing prior to generation of product or service. These can be grouped into three stages.

Input stage (S.No. 1): Application by Customer is termed as Request.

Process stage (S.Nos. 2,3,4,5,6). Processing of application is termed as a business process. It is a collection of activities designed to produce a specific output for a particular customer. Human interaction happens at this stage for recommendation/decision making. This is termed as Process.

Output stage (S.No.7). Delivery of product or service from a function is termed as Response

We identified a pattern called "Request-Process-Response" in customer centric government functions from this study. [i.e. Every request from customer is put through prescribed government process (business process) and response is delivered to customer]. Thus, the governments' function can be viewed in process centric approach as against traditional task oriented system.

This pattern has been verified and confirmed through the case studies conducted on four citizen centric government systems of the local government.

Thus, our study has identified a pattern called request-processresponse in a business process of customer centric Government system. This pattern provides decomposing functions into service oriented business processes. It is a new approach for development of customer centric system.

Table 1: A typical Processing stages for government functions

\begin{tabular}{|c|c|c|c|}
\hline $\begin{array}{l}\text { S. } \\
\text { No. }\end{array}$ & Item & Item Description & $\begin{array}{l}\text { Nature of } \\
\text { item }\end{array}$ \\
\hline 1 & $\begin{array}{l}\text { Submission of } \\
\text { Forms/ } \\
\text { Documents }\end{array}$ & $\begin{array}{l}\text { Necessary application } \\
\text { form(s) is/are duly filled, } \\
\text { relevant document(s) for } \\
\text { requested service/product } \\
\text { is/are submitted }\end{array}$ & May change \\
\hline 2 & Processing & $\begin{array}{l}\begin{array}{l}\text { Application is } \begin{array}{r}\text { processed } \\
\text { relevant }\end{array} \\
\text { with } \\
\text { statutes/rules/regulation/act/p } \\
\text { rocedure }\end{array}\end{array}$ & May change \\
\hline 3 & $\begin{array}{l}\text { Computing fees } \\
\text { or service } \\
\text { charges to be } \\
\text { paid }\end{array}$ & $\begin{array}{l}\text { Fees or service charges are } \\
\text { computed based on the } \\
\text { typical schemes/ prescribed } \\
\text { charts - notified time to time }\end{array}$ & May change \\
\hline 4 & $\begin{array}{lr}\text { Payment } & \text { of } \\
\text { fees/ } & \text { service } \\
\text { charges } & \\
\end{array}$ & $\begin{array}{l}\text { Payment is made as } \\
\begin{array}{l}\text { demanded for } \\
\text { product }\end{array}\end{array}$ & $\begin{array}{l}\text { Mode of } \\
\text { payment } \\
\text { may change }\end{array}$ \\
\hline 5 & Issue of receipt & $\begin{array}{l}\text { Payment accepted and } \\
\text { receipt is issued }\end{array}$ & $\begin{array}{l}\text { Formats } \\
\text { may change }\end{array}$ \\
\hline 6 & $\begin{array}{l}\text { Storing of } \\
\text { documents/ } \\
\text { record } \\
\text { management/ } \\
\text { updating }\end{array}$ & $\begin{array}{l}\text { Data/ information/ } \\
\text { documents/... are stored for } \\
\text { repository/ archival/ audit } \\
\text { /future requirements }\end{array}$ & $\begin{array}{l}\text { Schemes/ } \\
\text { devices may } \\
\text { change }\end{array}$ \\
\hline 7 & $\begin{array}{l}\text { Generation of } \\
\text { Outputs }\end{array}$ & $\begin{array}{l}\text { output is generated for } \\
\text { requested service or product }\end{array}$ & $\begin{array}{l}\text { Delivery } \\
\text { channels } \\
\text { may change }\end{array}$ \\
\hline
\end{tabular}




\subsection{Field Survey Results}

The interviews were conducted with Government officials, Domain experts, Developers, Internal users and Customers to understand their expectations from eGovernment system and difficulties existing in dealing with Information System.

\subsubsection{Government officials}

The management requires business processes to be automated in order to provide services / products to customers. The existing business processes are to be captured and documented. Then, business processes can be reviewed and analyzed for feasibility, possible simplification and/or optimization. The business processes are the key processes in government system. The management needs to understand the overview of the system with business processes and information flow. There is a gap found in describing business processes to management. They requested for a system description in a simple and understandable form, preferably in graphical notation. This will enable them to verify the correctness of the system prior to and after development of Information System.

Table 2: Citizen centric software systems for local government

\begin{tabular}{|l|l|l|l|}
\hline $\begin{array}{l}\text { Name of } \\
\text { function in } \\
\text { software } \\
\text { system }\end{array}$ & Request & Process & Response \\
\hline $\begin{array}{l}\text { Property Tax } \\
\text { payment }\end{array}$ & $\begin{array}{l}\text { Applying for } \\
\text { payment of tax }\end{array}$ & $\begin{array}{l}\text { Verification of } \\
\text { Property ID, } \\
\text { Property } \\
\text { details, } \\
\text { Scheme; tax } \\
\text { calculation, } \\
\text { accepting } \\
\text { Payment } \\
\text { receipt of tax }\end{array}$ \\
\hline $\begin{array}{l}\text { Issue } \\
\text { Khata } \\
\text { certificate }\end{array}$ & $\begin{array}{l}\text { Applying for } \\
\text { Khata } \\
\text { certificate for a } \\
\text { property }\end{array}$ & $\begin{array}{l}\text { Verification of } \\
\text { Property, } \\
\text { accepting } \\
\text { payment }\end{array}$ & $\begin{array}{l}\text { Issue of Khata } \\
\text { certificate }\end{array}$ \\
\hline $\begin{array}{l}\text { Property } \\
\text { Transfer }\end{array}$ & $\begin{array}{l}\text { Applying for } \\
\text { Property } \\
\text { transfer to } \\
\text { another owner }\end{array}$ & $\begin{array}{l}\text { verification of } \\
\text { documents, } \\
\text { approvals, tax } \\
\text { calculation, } \\
\text { issue of notice, } \\
\text { accepting fees, } \\
\text { generation of } \\
\text { order }\end{array}$ & $\begin{array}{l}\text { Issue } \\
\text { Property }\end{array}$ \\
\hline $\begin{array}{l}\text { Issue of Birth order } \\
\text { certificate }\end{array}$ & $\begin{array}{l}\text { Applying for } \\
\text { Birth certificate }\end{array}$ & $\begin{array}{l}\text { Verification of } \\
\text { hospital } \\
\text { records, } \\
\text { document, } \\
\text { accepting fees }\end{array}$ & $\begin{array}{l}\text { Issue of birth } \\
\text { certificate }\end{array}$ \\
\hline
\end{tabular}

\subsubsection{Domain experts}

The domain knowledge is available with domain experts. The business processes, tasks associated with each business process and products/services are known to them. However, they do not understand Information System and Processes. The developer is required to understand complete details of functional requirements and domain knowledge from domain experts. The domain experts presume that they have provided all the details about system, business processes and activities to developers. However, there could be some missing information or details not captured. There is a gap found in transferring knowledge about business processes to developers.

\subsubsection{Developers}

The domain knowledge in proper form is required for understanding system. The components of system like business processes, process logic, information flow, conditions, constraints, interactions of internal as well as external users etc. are required to be represented explicitly in understandable form. These are very complex and difficult to understand in short time. Multiple iterations are required to acquire this knowledge correctly. There is a gap found in understanding the business processes by developers.

\subsubsection{Internal users}

In government system, internal users carry out tasks manually. If they have to do it electronically, they need to understand what portions of their tasks are already automated and what portions of tasks are expected to be done manually through interactions. The internal user is required to understand business processes and process cycle of each business process to operate them properly. Their roles and their interactions in terms of verifications, recommendations and decision making are to be explicitly represented. The internal users are not familiar with eGovernment system and they take a long time to understand these operations. There is a gap found in operating business processes by internal users.

\subsubsection{Customers}

It should be service oriented. Detailed instructions should be provided for operation. Multiple delivery channels are required. Application forms and other statutory forms should be easy to understand and fill. Products should be made available on completion of required transactions. The Information System should be user friendly, easily understandable, easy to operate, anytime anywhere accessible and a speedy delivery of services or products. There is a gap in certain services, if business processes are not implemented properly.

From the above field survey results, we consolidated some of the technical gaps found in Requirements specifications generated from functional requirements of a system in Requirements Engineering stage:

- The function and business process may not be possible to separate in a system.

- The business processes identified under each function may not be complete.

- The business process may not be clear and not completely understood.

- The description of business process may not contain all details. Details may be missing.

- The activities may be bundled.

- The business rules defined for a business process may not address all scenarios. Exceptions may exist.

- The type of business rules and its linkages with other rules may not be direct.

- Some business rules are complex to understand, interpret and represent correctly.

- The existing practices of business process may not be known.

- The change of business rules may pose a problem. Handling of old rules and new rules need to be worked out properly.

- The manual intervention may not be clear in some cases.

The technical gaps listed above are not exhaustive. It is 
observed that the technical gaps create inaccuracies, incompleteness and unknown scenarios. So, system analyst is required to spend considerable time or multiple iterations with domain experts to close these gaps. If the product is developed with incomplete specifications, then the product may not represent the system requirements exactly. Hence, we investigated further to arrive at a suitable model to minimize these technical gaps.

\subsection{People, Process and Technology}

We investigated manual system of operations in the government system to understand behaviour of people and processes. By people, we mean the operating people. By process, we mean the business processes. The business processes are well defined. They describe the situations or cases and what to do at each situation or case. These provide guidelines and procedures to process application forms but do not perform the required actions. However, they are not static. The processes do change over time to accommodate changes effected in administration. The changes are documented and made available for use.

The operating people study business processes and acquire knowledge to perform required actions in delivering services and products to customers of the government. Over a period of time, operating people become experts in the area at which they work. However, they cannot do the same work over a long period in their service. They may have to move or change to different areas of work and thereby their expertise could be used in a particular area of work in the office for a limited time only. Hence, it is observed that people come and go but processes continue to remain. The knowledge or expertise also go with people and does not remain in organization. The operational efficiency also varies with people.

The use of technology in government organization changes its work system. The operating people started using computing devices such as calculators, computers etc. to assist them in calculations or computations. This led to transfer of certain manual work to devices. According to Alter, Information System is defined as "a particular type of work system that uses information technology to capture, transmit, store, retrieve, manipulate or display information, thereby supporting one or more other work systems"; work system is defined as " a system in which human participants perform a business process using information technology and other resources to produce products for internal customers" and information technology is defined as "the hardware and software used to [store, retrieve and transfer] information" [21]. The Information System as part of eGovernment is performing most of the processing work and has reduced the work of operating people considerably. However, the technology is changing rapidly.

This study has revealed that process is an important and complex entity among the three entities viz. people, process and technology. The process seems to be more stable compared to the other two. Hence, the process needs to be understood properly and represented precisely for the development of Information System. The process modeling will help designers and developers to understand the processes correctly and represent them in the Information System.

\subsection{Process Aware Information System}

We reviewed the literature to select an Information System that links business processes and information technology that can be effectively used in eGovernment system. We need to understand what business processes and Information Systems are and how these can be combined in order to help organizations function more effectively. A business process is a special type of process which can be defined as a set of tasks or actions that can be carried out in a specific order by assigned employees or other resources based on input data to produce necessary output data in satisfying business goals.

Process Aware Information System (PAIS) is defined as "A software system that manages and executes operational processes involving people, applications and/or information sources on the basis of process models. Information Systems that are process aware link information technology to business processes. By process, we mean a way for organizational entity to organize work and resources (people, equipment, information and so forth) to accomplish its aims." [22].

The components of PAIS are process definitions indicating the degree of adherence and type of participants like People or Applications. PAIS supports process driven approach and enables managers to understand overview of the entire process, monitor execution, track dependencies and facilitate process awareness in an organization [23].

PAISs has four types of process definitions viz. Tightly framed, Loosely framed, Adhoc framed and Unframed. A Tightlyframed system executes a process strictly based on a predefined process model. A typical example of this is a workflow system such as staffware or service oriented process management system. A Loosely framed system executes a process based on a model allowing deviations from its prescribed process flow. An Adhoc framed system executes a process model, which can be changed for each specific case by incorporating refinements. A process is defined as Unframed if it does not have a process model [24].

Based on the type of participants, the PAISs can be classified into three groups of processes and they are $\mathrm{P} 2 \mathrm{P}$ (Person-toPerson), P2A(Person-to-Application) and A2A(Application-toApplication). P2P processes involve humans in their tasks and hence does not fully support automation. P2A processes support people and applications. People are involved for decision making in Information System. A typical example of $\mathrm{P} 2 \mathrm{~A}$ process in PAIS is a workflow based system. The workflow system specifies how the activities are to be carried out with the participation of assigned people for decision making. A2A processes are used for communication or interaction between applications without intervention of people. $\mathrm{A} 2 \mathrm{~A}$ processes support transaction processing systems and enterprise application integration platforms. P2A and A2A processes may coexist in a larger system. A business process always aims to serve customers and parts of the process may be fully automated [24].

Based on our study and the discussions on PAISs, we propose Process Aware Information System to be a suitable Information System for a customer centric eGovernment system. The process model chosen by us in PAIS is tightly-framed and workflow system, which includes P2A and A2A process model. The proposed process model can meet work system of the government as observed in this study. We further define structure of our process model to be used for customer centric government system with the pattern identified by us in this study.

\subsection{Process Model}

The term 'process model' is used for representing a business process using a formal notation, preferably graphical notation as a blueprint describing the structure [25]. Process models are used for understanding, analyzing, redesigning and optimizing processes. It also captures working procedures with details required for execution of tasks envisaged. In a process model, 
process entities and the relationships between them are explicitly defined. This may be descriptive, prescriptive or explanatory $[25,26]$.

A software process model is defined as a representation of networked sequence of activities, objects, transformations and events that help in software development. The work distribution between people and processes in a software system have been described as "structured discourses of work" [27].

The view of Software process networks in terms of multiple interconnected chains has been referred [28,29]. The Task chains are popularly known as "workflow" [30].

The topology of Task chains can be linear or non-linear sequence of actions exhibiting system structure. The nonlinearity facilitates the representation of task chains in nondeterministic or iterative or multiple or parallel alternatives. Task chains can be represented in either prescriptive or descriptive action sequences. Prescriptive task chains describe how actions should be accomplished in a specific order. Descriptive task chains describe how actions are carried out based on events and situations that emerge during the process flow. The process model selected by us is descriptive task chains, which is multi-tier, nonlinear and iterative, to represent government functions.

\subsection{Process model for eGovernment system}

In our research study, we have considered a government functional unit ' $\mathbf{S}$ ' having a finite number of functions. The functions can be decomposed in terms of business processes. Each business process can be decomposed into a process chain using the pattern " request-process-response". To meet this service oriented approach, we define our process model to adopt a layered architecture. There are three layers. Layer-1 represents functions. Layer- 2 represents business processes. Layer-3 represents activities. The network of these layers with suitable path of execution represents the business process map of system (S). The detailed descriptions are as follows:

\subsubsection{Layer-1 represents Functions}

This consists of finite number of functions representing government functional unit and can be represented as $\mathbf{S}=\left\{\mathrm{f}_{1}, \mathrm{f}_{2}, \mathrm{f}_{3}, \ldots \ldots \ldots, \mathrm{f}_{\mathrm{n}}\right\}$ where $\mathrm{f}_{\mathrm{i}}$ is a function such that

- Each function is well defined and produces the desired product/service

- Each function can have one or more business processes.

\subsubsection{Layer-2 represents business processes}

Each function $\left(\mathrm{f}_{\mathrm{i}}\right)$ can be decomposed into business processes, which can be represented as

$$
f_{i}=\left\{b_{1}, b_{2}, b_{3}, \ldots \ldots ., b_{m i}\right\} \text { where } b_{j} \text { is a business }
$$
process such that

- $\quad$ Each business process operates on defined input(s)

- Customer generates Requests, which are random and asynchronous

- Customer generated request invokes the suitable business process under that function

- $\quad$ Each request is associated with a business process

- Each business process defines the core process logic

- Each business process produces a service or product as response (output)

\subsubsection{Layer-3 represents activities}

An activity (or work or task) defined here is at the lowest level. Each activity can be atomic and cannot be compound. The activity consists of process logic, which represents the internal operational procedures. The process model captures working procedures to fulfill envisioned activities under the business process. Each business process can be decomposed into an activity or a set of activities. The internal user interacts with the activity to perform his action. It is an activity oriented process model. A business process can be represented as

$$
b_{j}=\left\{a_{1}, a_{2}, a_{3}, \ldots \ldots, a_{k}\right\} \text { where } a_{n} \text { is an activity }
$$

This layer represents all the activities under a business process. This forms a descriptive task chain which is nonlinear, multitier and with iterative structure.

\subsubsection{Logic based approach}

The activities forming a descriptive task chain are envisioned to meet the objectives of a business process. The actions taking place in each activity provides a change in the state of a system. The actions are based on processing logic described formally by business rules, conditions and decisions. The activity follows logic based approach and generates reactions. Each activity can be expressed as tuples (E, C, A, P, EL) consisting of E- event, $\mathrm{C}$ - condition, $\mathrm{A}$ - action, $\mathrm{P}$ - post condition and EL- exception. This idea has been taken from literature under complex event processing in reactive systems to apply formally in activity [31]. This helps to represent activity as an abstraction involving these five parameters to describe dynamic behaviour of activity. If a parameter is not relevant for an activity, then it can be considered as blank in representation. Only relevant parameters can be addressed for an activity. This representation helps in understanding the activity. The event or condition triggers activity and actions are performed by activity based on processing logic. The activity generates post conditions and exceptions if any. If this activity could not generate any reaction in this situation or context, exceptions are generated for graceful handling further. This type of representation helps the analyst to generate specifications of activity during requirement analysis stage.

\subsubsection{Abstraction of process path structure}

The activities under a business process follows specified path. The path can use the following abstractions as determined by conditions in the business process.

- Sequential : Activities are connected in sequential path

- Concurrent : Activities are connected concurrently in more than one path

- Fork : Path is split into two or more paths

- Join : Two or more paths are joined into one path

- Choice-options: Multiple paths are available for selection

- Mutual exclusions: Paths are mutually exclusive

- Synchronous : Paths are synchronized

- Asynchronous : Paths are asynchronized

- Loop : Path is enabled for loop back in the chain

- Dead end : Path is terminated

The business process map of eGovernment system can be graphically represented as given in Fig. 1.This gives a hierarchical structure with all the three layers. 


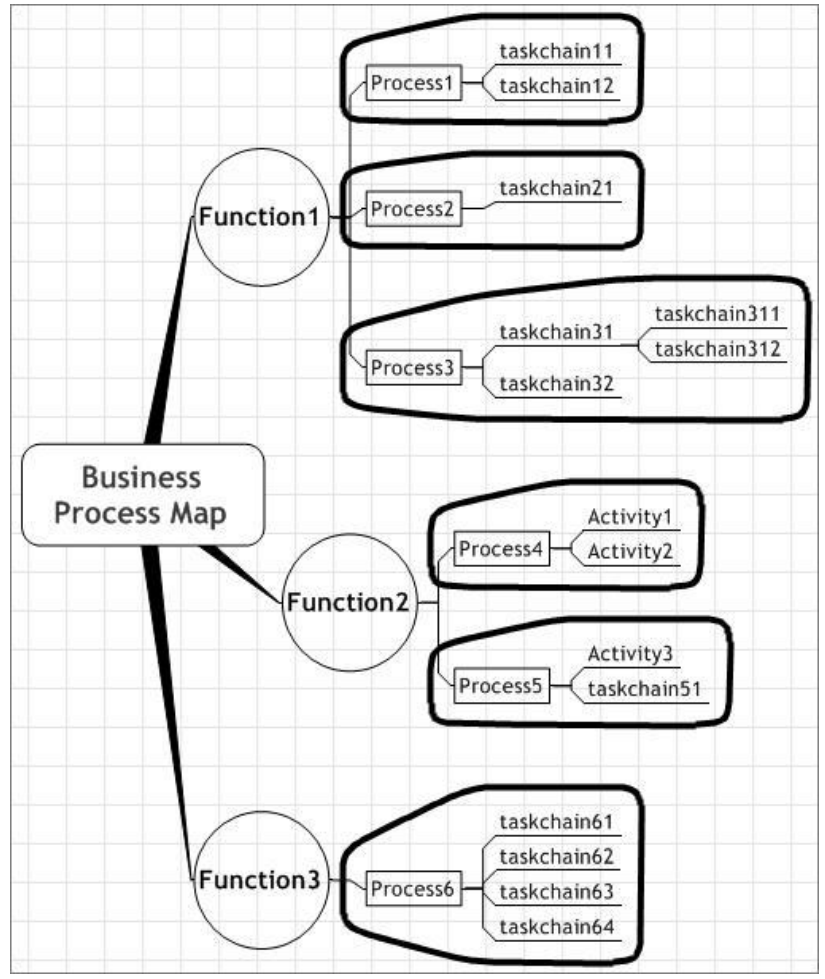

Figure 1: Business Process Map of a System

The structure of process model for a business process proposed for eGovernment system is a multi-tier, non-linear and iterative structure with multiple interconnected descriptive task chains. The schematic diagram of the structure of our process model for a business process in customer centric eGovernment system is given in Fig. 2.

In this process model, Customer request is sent as an event (e1). This event selects a function (f1) and business process $4 \mathrm{~b} 1$ ) under this function. Then, activities under this business process are interconnected with predefined control flow using conditions at each stage until it reaches end of the process. On successful completion, response is delivered to the customer. This exhibits end-to-end processing of request.

We have already proposed Petri Nets (PN) as a formal modeling language for Customer centric eGovernment system, which is modeled as Discrete event driven system. The graphical representation of PN describes dynamic behaviour of system. Petri Nets enable the visualization of the modeled system state changes. The process cycle can be expressed in terms of occurrence of events and conditions in a system [32]. The PN can be used as the formal modeling language for representing our process model described in this paper.

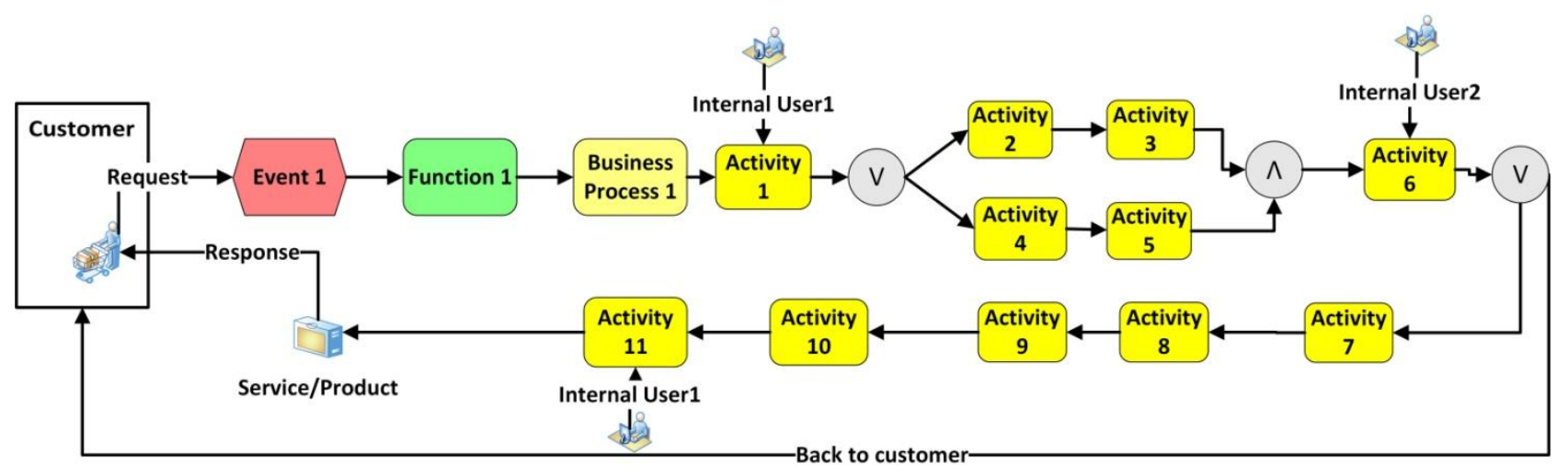

Figure 2: Structure of business process model of eGovernment system 


\section{DISCUSSIONS}

The use of our process model for an eGovernment System has the following advantages:

- Information System developed based on this model is process centric.

- Information can be routed automatically and efficiently to generate responses to customers.

- Integration with other systems can be done for information exchange and for availing services.

- Business processes can be represented very efficiently.

- Helps to redesign and optimize the existing business processes.

- Provides better communication and illustration of the process to the management for monitoring and control.

- Enables to track dependencies in execution of tasks and facilitates process awareness in the organization.

We suggest that each business process can address only one concern. Each activity can be independent and address only one unit of work. This increases flexibility in changing business processes. This process model is configured to describe work allocation under each business process and is supported by human participation for decision making. Also, some business processes can be configured to support back-end operations or Application-to-Application communication. Using these two configurations (P2A and $\mathrm{A} 2 \mathrm{~A}$ processes), functions of eGovernment system can be supported.

We have derived eGovernment system as an event (request) driven system. This process model can be used as a blueprint of system to be developed. Multiple iterations using this business process map can be done for closing the gaps found. This business process map can be reviewed by all stakeholders for completeness and accuracy. This process map is not technology dependent. Hence, this can be easily understandable and will not become invalid.

\section{CASE STUDY}

A citizen centric system developed for property tax management as eGovernment system for local government has been taken for illustration for this process model. The property tax management includes major functional requirements such as Registration of properties, Mutation of properties, Issue of khata certificate and Khata extract, Payment of property tax Accounting and Reports generation. This application facilitates citizens to apply for services related to their properties of different types and usage, in online mode and using One stop service centres. This application supports front office and back office related to property tax management [33]. This application is a process centric model which has been illustrated in Figure 3 wherein, the task chains are shown in expandable mode with a sign $\oplus$. By clicking this, the task chain will expand and provide the complete process path as per our process model. This provides insight into the chain of activities, interactivity, conditions and control flow.

The business process map helped to redesign the processes. It also helped to simplify the processes and remove unnecessary stages after analyzing business process map. The domain experts and management could understand the process flow. It manifests the business process map of the entire system. This business process map can be updated if new requirements are added and the existing requirements are modified or deleted. This business process map was found to be very useful to understand about this application by all stakeholders. The templates provided for all the components (functions, processes and activities) have been used effectively. The description of procedure(s), business rules and other specific conditions to be used at each activity level has increased the understanding of the system. This system is running successfully. Citizen can access information and request for services any time from various service centres. 


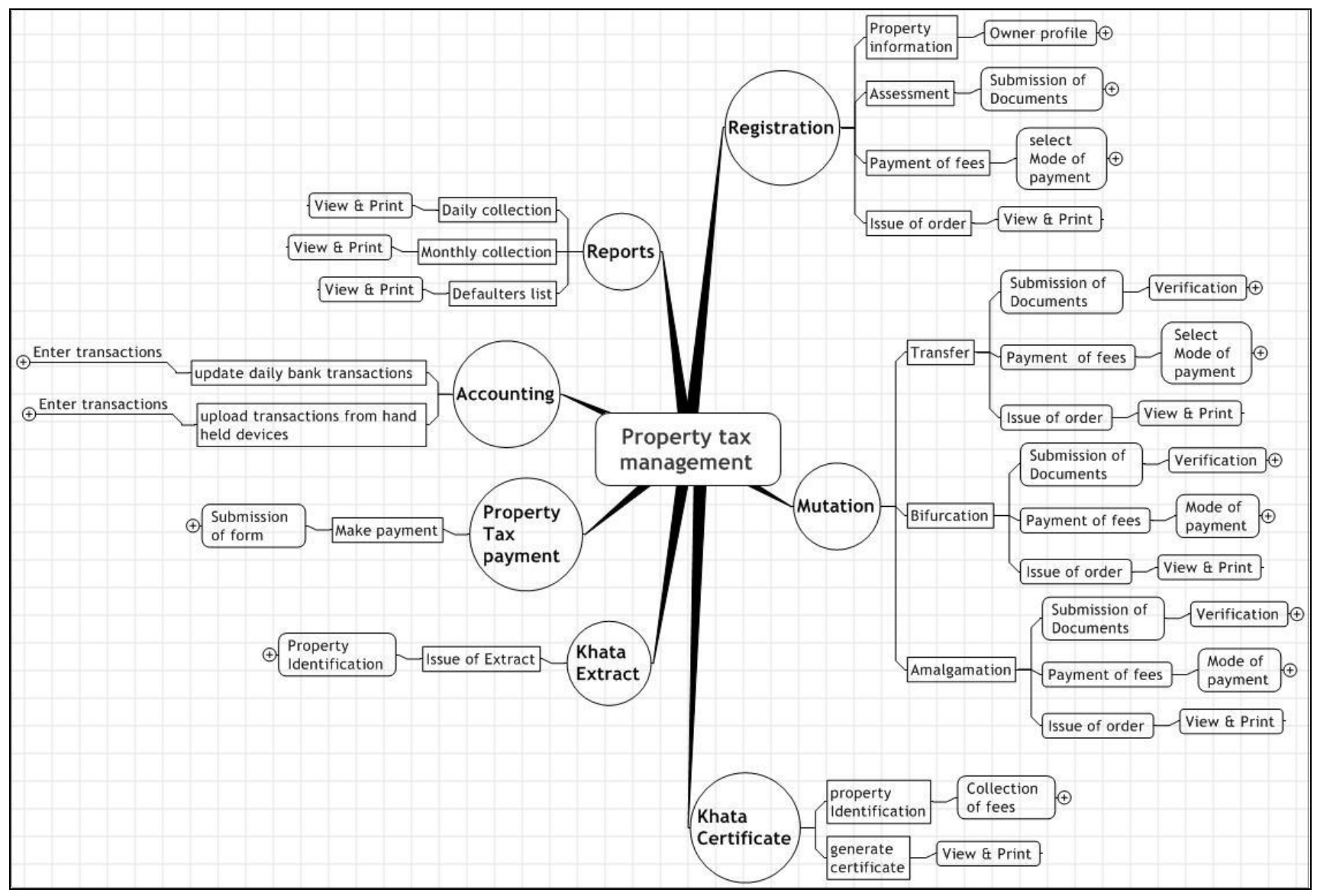

Figure 3: Business process map for property tax management- A citizen centric application

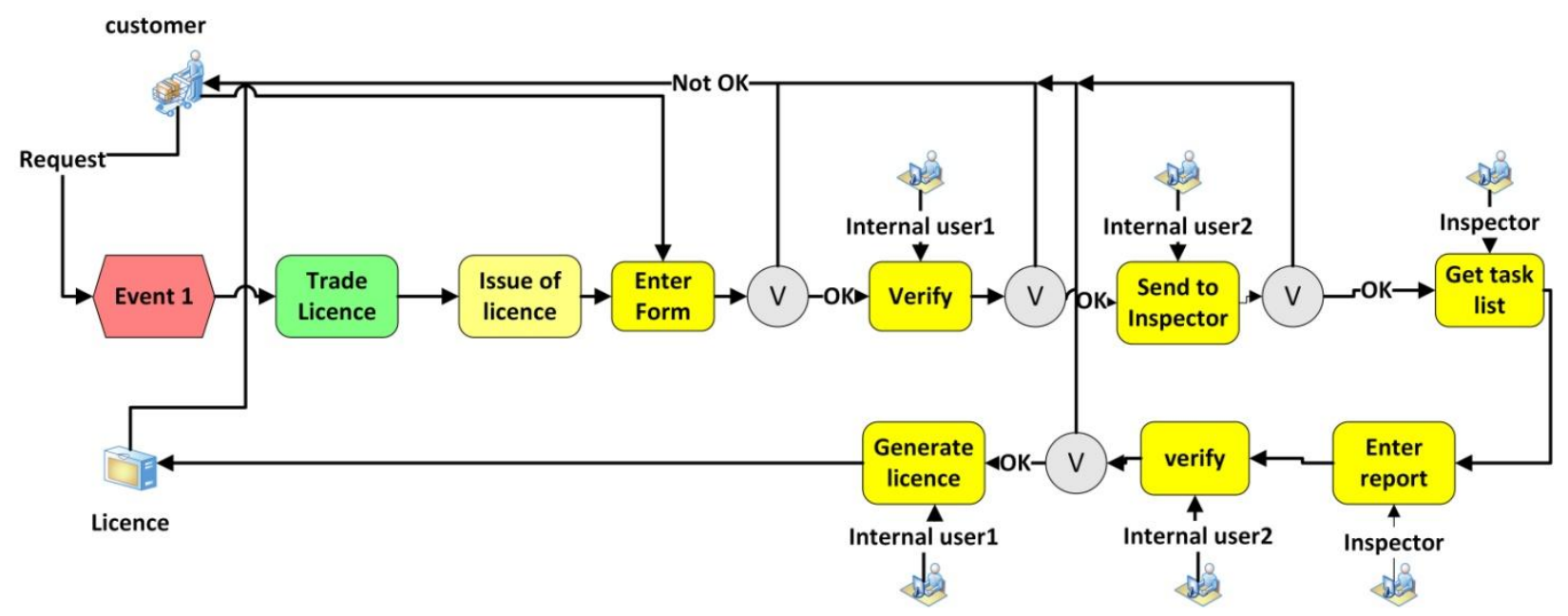

Figure 4: Process model for Issue of trade licence for a customer 


\section{CONCLUSIONS}

The introduction of eGovernment system is basically to transform from task-centric mode of working to process-centric mode of working supported by Information System. The Information System represents business processes to help government system function more effectively. The business processes are complex in government system. The business processes are required to be understood clearly prior to development of Information System. This research study was carried out to propose a suitable business process model and Information System for customer centric eGovernment system.

This study has revealed that work system in eGovernment can be described as an event (Request) driven system with a pattern Request-Process-Response. The Process Aware Information System (PAIS) is a suitable Information System for a customer centric eGovernment system. The process model chosen in PAIS is tightly-framed and workflow system, which includes P2A(Person-to-Application) and A2A(Application-toApplication) process model. The structure of process model proposed for eGovernment system is a multi-tier, non-linear and with iterative structure and can be with multiple interconnected descriptive task chains. The work articulation can be represented as descriptive task chains to follow a planned task sequence determined by conditions and situations emerged during process cycle. The activity can be represented as tuples (E,C,A,P,EL).

This model provides business process map of the entire system in process centric approach. This business process model will serve as a blueprint for system. This model will help nontechnical users, architects and developers to understand system and its capabilities. This business process model is not dependent on technology and can be used for implementing desired technology platform. The model does not get invalidated due to obsolescence of technology. This business process map needs to be updated as and when changes are made to the system. Our process model helps to clearly represent requirement specifications in terms of functions, business processes and activities.

\section{ACKNOWLEDGEMENTS}

This research work was carried out under Department of CSE, Dr.MGR Educational and Research Institute, Chennai, India. The authors thank Chairman, ISRO and Scientific Secretary, ISRO for their support.

\section{REFERENCES}

[1] Moon, M. J, 2002, The evolution of E-Government among municipalities: Rhetoric or Reality, public Administration review, July/August, vol. 62, No.4, pp.424-433.

[2] Sprecher, M.H., 2000, Racing to e-government: Using the Internet for citizen service delivery, Government Finance review, Vol. 16, 5, pp 21-22.

[3] Darrel West (2004), E-Government and the transformation of Service Delivery and Citizen Attitudes, Public Administration Review, January/February, Vol.64, No.1, pp 15-27.

[4] Heeks. R., 2003, Most e-Government -for-Development Projects Fail How can Risks be Reduced, IDPM

[5] Jackson,M., 1995, Software Requirements \& Specifications- A Lexicon of Practice, Principles and Prejudices, ACM Press, Addison-Wesley.
[6] Parnas, D.L. and Madey, J., 1995, Functional Documents for Computer Systems, Science of Computer Programming, Vol. 25, pp. 41-61.

[7] Mylopoulos, J., Chung, L., Nixon, B., 1992, Representing and Using Non functional Requirements: A Processoriented Approach, IEEE Trans. on Software Engineering, Vol. 18, No. 6, June, PP. 483-497.

[8] Dardenne, A., Van Lamsweerde, A. and Ficas, S., 1993, Goal Directed Requirements Acquisition, Science of Computer Programming, Vol. 20, pp. 3-50.

[9] Meyer,B, 1985, On formalism in Specifications, IEEE Software, January,Vol. 2, No. 1, pp. 6-26.

[10] Loucopoulos, P., and Karakostas, V., 1995, System Requirements Engineering, McGraw-Hill Book Company, Europe.

[11] Lamsweerde, A.V., 2000, Requirements Engineering in the year 00: A Research Perspective, ICSE, Limerick, Ireland, pp.5-19.

[12] Zhiyuan Fang, 2002, E-Government in Digital Era: Concept, Practice and Development, International journal of The Computer,The Internet and management, Vol. 10, No. 2, pp. 1-22.

[13] Karen layne and Jung woo Lee, 2001, Developing fully functional E-Government: A four stage model, Government Information Quarterly, 18, pp. 122-136.

[14] Reddick, C.G, 2005, Citizen Interaction with eGovernment: From the streets to servers, Government Information Quarterly- 22, pp. 38-57.

[15] Centeno C, van Bavel R and Burgelman JC, (2005), “ A Prospective view of E-Government in the European Union" The Electronic Journal of e-Government Volume 3 Issue 2, pp 59-66.

[16] Corradini F, Polzonetti A and Riganelli O, (2009) "Business Rules in E-Government applications" Electronic Journal Of e_Government Volume \& Issue 1, , pp 45-54.

[17] Carlo Simon, Sebastian Olbrich, 2005, The Influence of Legal Constraints on Business Process Modeling, eGovernment Workshop '05 (eGOV05), Brunel University, West London,UB8 3PH, UK, September

[18] Silke Palkovits, Maria A. Wimmer, (2003) “ Processes in e-Government - A Holistic framework for Modelling Electronic Public Services", Electronic Government, Springer.

[19] Merriam, S.B.,1998, Qualitative Research and Case Study Applications in Education, Revised and Expanded from Case Study Research in Education, San Francisco, JosseyBass.

[20] Creswell, J.W, 2005, Educational Research: Planning, Conducting and Evaluating Quantitative and Qualitative research $\left(2^{\text {nd }} E d\right)$, Upper Saddle River, NJ: Pearson.

[21] Alter, S., 1999, Information Systems: A Management Perspective, Addison-Wesley, reading, MA.

[22] Sharp, A. and McDermott, P., 2001, Workflow Modeling: Tools for Process Improvement and Applications Development, Artech House, Norwood, MA. 
[23] Dumas, M., Van der Aalst, W.M.P,and HofBtede, A.H.M.T, 2005, Process-Aware Information Systems, Wiley.

[24] W.M.P. van der Aalst, Process Aware Information Systems: Lessons to be Learned from Process mining, http://wwwis.win.tue.nl/ wvdaalst/publications/p522.pdf

[25] Weske,M., 2007, Business Process Management: Concepts, languages, Architectures, Springer - Verlag.

[26] Davenport, T., (1993), Process innovation: Reengineering work through information technology, Harvard business school press, Boston

[27] Winograd, T. and Flores, F., 1986, Understanding Computers and Cognition: A New Foundation for Design, Ablex Publishers, Lexington, MA.

[28] Kling, R. and Scacchi, W., 1982, The Web Computing: Computer Technology as Social Organization, Advances in Computers, 21, pp. 1-90, Academic Press, New York.
[29] Garg, P.K. and Scacchi, W., 1989, ISHYS:Design of an Intelligent Software Hypertext Environment, IEEE Expert, 4,3 , pp. 52-63.

[30] Bolcer,G.A. and Taylor, R.N., 1998, Advances workflow management technologies, Software Improvement and Practice, 4,3, pp. 125-171.

[31] Paschke, A., Kozlenkov, A. and Boley, H., 2007, A homogenous reaction rules language for complex event processing, In International Workshop on Event Driven Architecture for Complex Event Process.

[32] Ramani, S. and Y.S. Kumaraswamy, 2012, Modeling of Customer Centric eGovernment System using Petri Nets, IJCA Proceedings on Egovernance and Cloud Computing Services- 2012, EGOV(1): pp. 31-40, December.

[33] Ramani S, Aradhya.H.B.S, Lingaraj Urs, 2003, Property tax Reforms and online collection, National conference on good governance held at New Delhi, June. 